\title{
Relationship between platelet aggregation and stroke risk after percutaneous coronary intervention: a PENDULUM analysis
}

\author{
Yuji Matsumaru' ${ }^{1}$ Takanari Kitazono $^{2} \cdot$ Kazushige Kadota $^{3} \cdot$ Koichi Nakao $^{4} \cdot$ Yoshihisa Nakagawa $^{5} \cdot$ Junya Shite $^{6}$. \\ Hiroyoshi Yokoi ${ }^{7} \cdot$ Ken Kozuma $^{8} \cdot$ Kengo Tanabe $^{9} \cdot$ Takashi Akasaka $^{10} \cdot$ Toshiro Shinke $^{11} \cdot$ Takafumi Ueno $^{12}$. \\ Atsushi Hirayama ${ }^{13} \cdot$ Shiro Uemura ${ }^{14} \cdot$ Takeshi Kuroda $^{15}$. Atsushi Takita ${ }^{16}$. Atsushi Harada ${ }^{17} \cdot$ Raisuke lijima $^{18}$. \\ Yoshitaka Murakami $^{19} \cdot$ Shigeru Saito $^{20} \cdot$ Masato Nakamura $^{18}$
}

Received: 23 September 2021 / Accepted: 26 November 2021 / Published online: 1 January 2022

(c) The Author(s) 2021

\begin{abstract}
In patients undergoing percutaneous coronary intervention (PCI) with a stent, high on-treatment platelet reactivity may be associated with an increased risk of stroke. This post hoc analysis of the PENDULUM registry compared the risk of post-PCI stroke according to on-treatment $\mathrm{P} 2 \mathrm{Y}_{12}$ reaction unit (PRU) values. Patients aged $\geq 20$ years who underwent PCI were stratified by baseline PRU (at 12 and $48 \mathrm{~h}$ post-PCI) as either high (HPR, $>208$ ), optimal (OPR, $>85$ to $\leq 208$ ), or low on-treatment platelet reactivity (LPR, $\leq 85)$. The incidences of non-fatal ischemic and non-ischemic stroke through to 12 months post-PCI were recorded. Almost all enrolled patients (6102/6267 [97.4\%]) had a risk factor for ischemic stroke, and most were receiving dual antiplatelet therapy. Of the 5906 patients with PRU data (HPR, $n=2227$; OPR, $n=3002$; LPR, $n=677$ ), 47 had a non-fatal stroke post-PCI (cumulative incidence: $0.68 \%$, ischemic; $0.18 \%$, non-ischemic stroke). Patients with a non-fatal ischemic stroke event had statistically significantly higher post-PCI PRU values versus those without an event $(P=0.037)$. The incidence of non-fatal non-ischemic stroke was not related to PRU value. When the patients were stratified by PRU $\leq 153$ versus $>153$ at $12-48 \mathrm{~h}$ post-PCI, a significant difference was observed in the cumulative incidence of non-fatal stroke at 12 months $(P=0.044)$. We found that patients with ischemic stroke tended to have higher PRU values at $12-48 \mathrm{~h}$ after PCI versus those without ischemic stroke.
\end{abstract}

Clinical trial registration: UMIN000020332.

Keywords Ischemic stroke $\cdot$ Platelet aggregation $\cdot$ Stents $\cdot$ Thrombosis

\section{Introduction}

Worldwide, stroke is one of the leading causes of disability and mortality [1] and is a major healthcare issue across Asia [2]. Data reported in 2013 showed that the incidence rates of stroke were 422/100,000 person-years [PY] for men and 212/100,000 PY for women in Japan, and the most common type of stroke in Japanese individuals is reported to be ischemic stroke (75.4\%) [2].

Current Japanese guidelines state that antiplatelet agents, such as aspirin or clopidogrel, should be used for the secondary prevention of ischemic stroke [3]. Until recently, monotherapy was the established regimen [4]. However, the

Yuji Matsumaru

yujimatsumaru@md.tsukuba.ac.jp

Extended author information available on the last page of the article
CHANCE trial, which compared 21 days of dual antiplatelet therapy (DAPT; clopidogrel plus aspirin) with aspirin alone in patients with mild stroke or transient ischemic attack within $24 \mathrm{~h}$ of onset, showed a significant benefit of DAPT in preventing recurrent stroke at 3 months without increasing bleeding events [5]. In contrast, the POINT trial compared 90 days of DAPT (clopidogrel plus aspirin) with aspirin alone and found a similar significant reduction in myocardial infarction (MI) and cardiovascular death at 3 months with DAPT, but there was a significant increase in major bleeding [6]. Based on this evidence, the Japanese guidelines recommended DAPT for 3 weeks after a stroke [3].

For some patients diagnosed with a stroke, response to antiplatelet treatment is poor [7], resulting in a recent investigative focus on the phenomenon of high on-treatment platelet reactivity (HTPR). For patients with HTPR, there is a negative impact on their clinical course, worsened prognosis, 
and an increased risk of recurrent vascular events [7, 8]. However, there is a paucity of definitive data on the topic since many reports are based on a small number of cases. Several researchers have used meta-analysis methodology to pool available information. The findings indicate that HTPR occurs in up to $65 \%$ of patients receiving antiplatelet monotherapy and 35\% of those receiving DAPT [9-11], and that it doubles the risk of stroke/transient ischemic attack $[10,11]$.

Antiplatelet agents are prescribed for secondary prevention of thrombotic events, including cardiovascular death, ischemic stroke, MI, and stent thrombosis, in patients who have undergone percutaneous coronary intervention (PCI) with a stent $[12,13]$. In the prospective ADAPT-DES registry including 11 US and European hospitals, data collected from 8665 patients who were prescribed aspirin and clopidogrel following placement of a drug-eluting stent (DES) indicated that HTPR on clopidogrel was related to stent thrombosis $(P=0.01)$ and MI $(P=0.001)$, and HTPR on clopidogrel and aspirin was inversely related to bleeding ( $P=0.002$ and $P=0.04$, respectively) [14].

However, there are no reports of large-scale studies in East Asian populations that have measured $\mathrm{P}_{2} \mathrm{Y}_{12}$ reaction unit (PRU) values and examined the association with stroke. This is particularly important as East Asian individuals have a high bleeding risk and a low thrombotic risk compared with other races and ethnicities $[15,16]$. The PENDULUM (Platelet rEactivity in PatieNts with DrUg eLUting stent and balancing risk of bleeding and IscheMic event) registry is a prospective, multicenter observational study of $>6000$ Japanese patients who have undergone PCI with DES; in the published analysis of 1-year data, high PRU values ( $>208$ ) measured at $12-48 \mathrm{~h}$ post-PCI were reported to be associated with cardiovascular events, but no association was found with hemorrhagic events [17].

The current post hoc analysis of data from the PENDULUM registry was conducted specifically to compare the risk of stroke after PCI according to PRU values.

\section{Materials and methods}

\section{Study design and patients}

Full details of the prospective, multicenter PENDULUM registry have been published [17]. In brief, patients who underwent PCI were enrolled between December 2015 and June 2017 from 67 medical institutions across Japan. In principle, all eligible patients were registered; the key eligibility criteria were age $\geq 20$ years, an indication for PCI with DES, and administration of antiplatelet drugs. Treatment (drug type, dosage, and duration) was at the discretion of the attending physician. DAPT was based on the standard of care in Japan at the time the study was conducted (aspirin, $100 \mathrm{mg}$ once daily [QD], increasing to $300 \mathrm{mg}$ QD; clopidogrel, $300 \mathrm{mg}$ loading dose, followed by $75 \mathrm{mg}$ QD; prasugrel, $20 \mathrm{mg}$ loading dose, followed by $3.75 \mathrm{mg}$ QD). All patients provided written informed consent before study participation.

For the current analysis, patients were stratified by baseline PRU value [18] into three categories: high ontreatment platelet reactivity (HPR; PRU $>208$ ), optimal on-treatment platelet reactivity (OPR; PRU $>85$ to $\leq 208$ ), and low on-treatment platelet reactivity $(\mathrm{LPR} ; \mathrm{PRU} \leq 85)$. The VerifyNow ${ }^{\circledR}$ system (Instrumentation Laboratory, Bedford, MA, USA) was used to measure platelet reactivity, and results were reported in PRU. Mandatory measurements were performed between 12 and $48 \mathrm{~h}$ post-index PCI, with subsequent optional measurements collected whenever possible.

The study was performed per the principles of the Declaration of Helsinki, and the Ethical Guidelines for Medical and Health Research Involving Human Subjects and was registered in the University hospital Medical Information Network (UMIN) Clinical Trial Registry (UMIN000020332). The study protocol and related documents were approved by the Ethics Committee at Toho University Ohashi Medical Center on 14 December 2015 (reference code: 15-71).

\section{Outcomes}

Outcomes evaluated in this post hoc analysis were the incidences of non-fatal ischemic stroke and non-fatal nonischemic stroke in each patient subgroup. Stroke was classified into ischemic stroke and non-ischemic stroke (hemorrhagic stroke, i.e., cerebral hemorrhage and subarachnoid hemorrhage). Non-fatal stroke was defined as a new neurological sign or symptom with a responsible lesion confirmed by computed tomography (CT) or magnetic resonance imaging (MRI). Ischemic stroke was defined as a new neurological sign or symptom with a new associated infarct confirmed by CT or MRI examination, regardless of whether neurological signs or symptoms persisted for more than $24 \mathrm{~h}$.

\section{Statistical analysis}

Kaplan-Meier analysis was done to show the incidences of events through to 12 months after the index PCI. For individuals who had multiple events of the same outcome, only the first event was counted. Patients who discontinued the study and those alive at the end of the observation period were censored. Univariate Cox regression models were used to estimate the hazard ratios (HR) and the $95 \%$ confidence intervals (CI), with OPR data used as reference. Summary statistics for PRU values at $12-48 \mathrm{~h}$ post-PCI were calculated for patients with or without each event; $P$ values were calculated using $t$-test. Receiver-operating 
characteristic (ROC) analysis was performed to assess the association between PRU and post-PCI events. Statistical analyses were conducted using SAS version 9.4 (SAS Institute, Inc., Cary, NC, USA). All statistical tests were two-sided with a $5 \%$ level of significance.

\section{Results}

\section{Patients}

In total, 6422 patients were registered in the PENDULUM registry, of whom 6267 were included in the full analysis set. Among the evaluable patients, 2278/6267 $(36.3 \%)$ were using beta-blockers. Common comorbidities included hypertension (5186/6267 [82.8\%]), hyperlipidemia (4919/6267 [78.5\%]), chronic kidney disease (estimated glomerular filtration rate $[$ GGFR] $\leq 60 \mathrm{~mL} /$ $\min / 1.73 \mathrm{~m}^{2} ; 2691 / 6267$ [42.9\%]), and diabetes mellitus (2767/6267 [44.2\%]). In addition, there were 655/6267 $(10.5 \%)$ patients with a history of ischemic stroke and $124 / 6267(2.0 \%)$ with a history of cerebral hemorrhage [17].

5906 patients had PRU data available and were included in the present evaluation. Background details according to PRU (HPR, $n=2227$; OPR, $n=3002$; and LPR, $n=677$ ) have been reported [17]. In brief, HPR patients had a mean age of 71.8 years, 989/2227 (44.4\%) were aged $\geq 75$ years, and 1650/2227 (74.1\%) were male. Respective characteristics of OPR patients (69.1 years; 979/3002 [32.6\%] $\geq 75$ years; and 2451/3002 [81.6\%] male) and LPR patients (68.5 years; 227/677 [33.5\%]; and $528 / 677[78.0 \%])$ were generally similar.

\section{Outcomes}

Overall, 51/6267 patients had a non-fatal stroke within 1 year after PCI. Of these, 40 patients had a non-fatal ischemic stroke (cumulative incidence $0.68 \%$; 95\% CI, 0.50-0.93) and 11 patients had a non-fatal non-ischemic stroke (cumulative incidence $0.18 \%$; 95\% CI, 0.10-0.33) (Fig. 1). In 5906 patients with available PRU, 37 patients had a nonfatal ischemic stroke (cumulative incidence $0.67 \%$; $95 \% \mathrm{CI}$, $0.48-0.92$ ) and 10 patients had a non-fatal non-ischemic stroke (cumulative incidence $0.18 \%$; 95\% CI, 0.10-0.33).

PRU values in patients with and without non-fatal stroke events are shown in Table 1 and Fig. 2. Patients with an event of non-fatal ischemic stroke had statistically significantly higher post-PCI PRU values than patients without an event $(P=0.037)$. Conversely, there was no significant difference in PRU between patients with a non-fatal nonischemic stroke event and those without an event.

The cumulative incidence of non-fatal ischemic stroke by PRU category is shown in Fig. 3a. The cumulative incidence of events tended to increase as the PRU level increased, but the differences were not statistically significant. The incidence of non-fatal non-ischemic stroke was not related to PRU value (Fig. 3b).

The incidence of stroke (all events and by stroke type) according to patient characteristics are shown in Table 2 . The atherothrombotic and lacunar stroke incidences increased with higher PRU values, but similar tendencies were not observed for cardiogenic stroke. Almost all patients (6102/6267 [97.4\%]) had a risk factor for ischemic stroke (i.e., history of ischemic stroke, diabetes, hyperlipidemia, chronic kidney disease, or hypertension). Of the 40 patients
Fig. 1 Cumulative incidence of stroke from 0 to 12 months after percutaneous coronary intervention

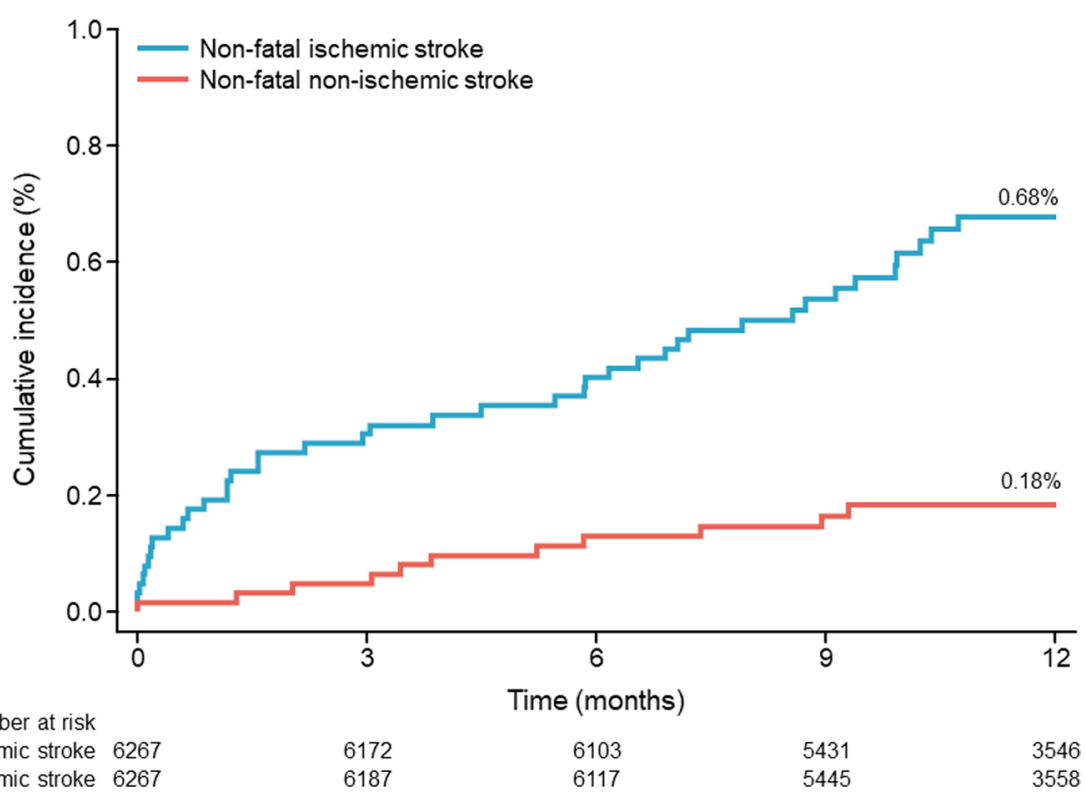


Table 1 P2 $\mathrm{Y}_{12}$ reaction units at 12-48 h after percutaneous coronary intervention in patients who did or did not suffer a non-fatal stroke event

\begin{tabular}{lll}
\hline P2Y & \multicolumn{2}{l}{ Non-fatal ischemic stroke } \\
\cline { 2 - 3 } & Yes $(n=37)$ & No $(n=5869)$ \\
\hline Mean (SD) & $208.5(67.0)$ & $182.0(77.1)$ \\
HPR, $n(\%)$ & $17(45.9)$ & $2210(37.7)$ \\
OPR, $n(\%)$ & $18(48.6)$ & $2984(50.8)$ \\
LPR, $n(\%)$ & $2(5.4)$ & $675(11.5)$ \\
\hline & Non-fatal non-ischemic stroke & \\
\cline { 2 - 3 } & Yes $(n=10)$ & No $(n=5896)$ \\
\hline Mean $(\mathrm{SD})$ & $178.4(95.7)$ & $182.2(77.1)$ \\
HPR, $n(\%)$ & $3(30.0)$ & $2224(37.7)$ \\
OPR, $n(\%)$ & $5(50.0)$ & $2997(50.8)$ \\
LPR, $n(\%)$ & $2(20.0)$ & $675(11.4)$ \\
\hline
\end{tabular}

$H P R$ high $\mathrm{P} 2 \mathrm{Y}_{12}$ reaction unit value, $L P R$ low $\mathrm{P} 2 \mathrm{Y}_{12}$ reaction unit value, $O P R$ optimal $\mathrm{P} 2 \mathrm{Y}_{12}$ reaction unit value, $S D$ standard deviation

Fig. $2 \mathrm{P} 2 \mathrm{Y}_{12}$ reaction units at $12-48 \mathrm{~h}$ after percutaneous coronary intervention according to the incidence of non-fatal ischemic stroke and non-fatal non-ischemic stroke. The box shows the 1st quartile, the 2nd quartile (median), and the $3 \mathrm{rd}$ quartile. The upper and lower bars show the measured values farthest from the median within 1.5 IQR from the box. Outliers of more than 1.5 IQR from the box are denoted by.$+ I Q R$ interquartile range, $N S$ not significant, $P C I$ percutaneous coronary intervention, $P R U$ $\mathrm{P} \mathrm{Y}_{12}$ reaction unit. $* P<0.05$
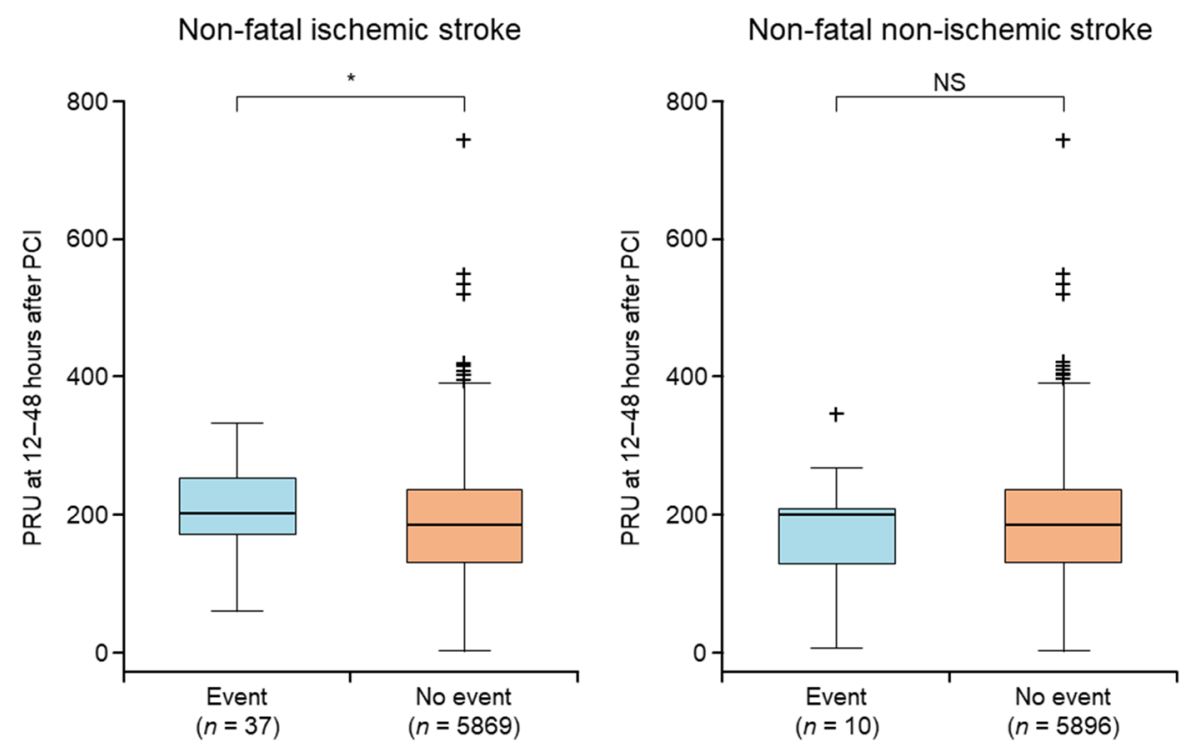

with non-fatal ischemic stroke, $36(90.0 \%)$ patients received DAPT at the time of the event.

The status of antiplatelet therapy at the time of the first event is shown in Online Resource 1. Most patients were receiving DAPT.

The area under the curve (AUC) and cutoff values of the ROC analysis for each outcome of this study are shown in Online Resource 2. As the representative values all had a low predictive ability, we focused on the CI; it was considered significant if the CI did not cross 0.5 . Thus, the AUC of the ROC curve was significant at $0.601(0.516-0.686)$ for non-fatal ischemic stroke but not at $0.508(0.309-0.707)$ for non-fatal non-ischemic stroke. The cutoff for non-fatal ischemic stroke was a PRU of 153. When patients were stratified by PRU $\leq 153$ versus $>153$ at $12-48 \mathrm{~h}$ post-PCI, the cumulative incidence of non-fatal ischemic stroke at 12 months post-PCI was significantly associated with PRU (HR 0.43, 95\% CI 0.19-0.98, $P=0.044$; Fig. 4).

\section{Discussion}

In this post hoc analysis of data from the prospective multicenter PENDULUM registry, we found that 47/5906 Japanese patients who underwent PCI and implantation of DES had a non-fatal stroke (37 ischemic strokes and 10 non-ischemic strokes) within 1 year after PCI. Additionally, post-PCI PRU levels were significantly higher among patients with a non-fatal ischemic stroke than those without a non-fatal ischemic stroke. 
Fig. 3 Incidence of stroke according to $\mathrm{P} 2 \mathrm{Y}_{12}$ reaction unit value. A Non-fatal ischemic stroke. B Non-fatal nonischemic stroke. $C I$ confidence interval, $H P R$ high $\mathrm{P}_{12}$ reaction unit value, $H R$ hazard ratio, $L P R$ low $\mathrm{P} 2 \mathrm{Y}_{12}$ reaction unit value, $O P R$ optimal $\mathrm{P} 2 \mathrm{Y}_{12}$ reaction unit value, $P R U \mathrm{P} 2 \mathrm{Y}_{12}$ reaction unit

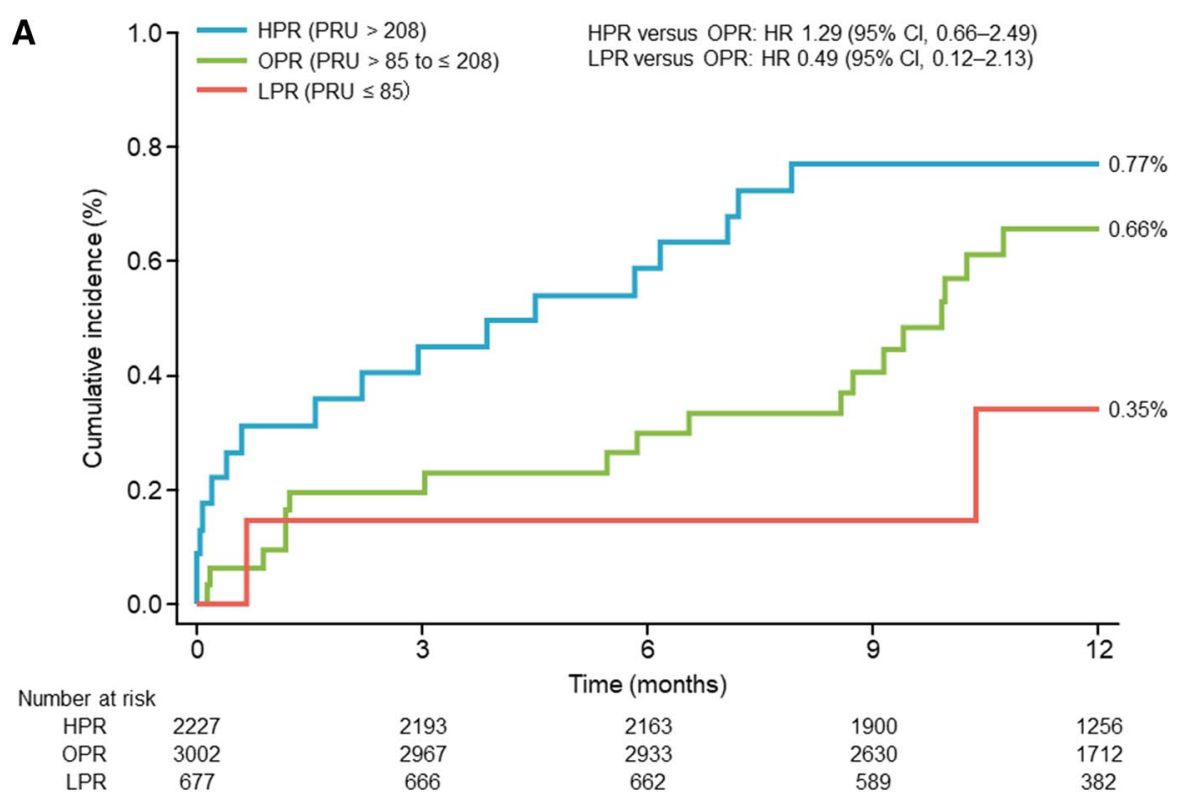

B

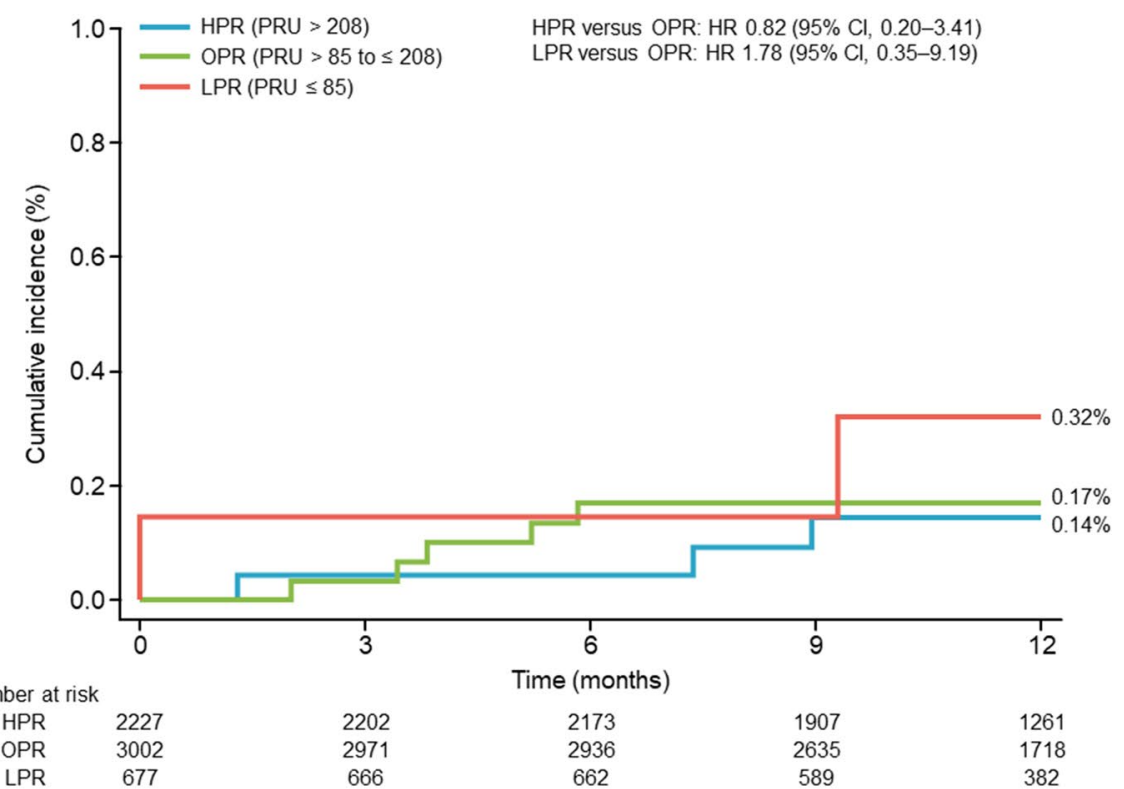

\section{Ischemic stroke risk in $\mathrm{PCl}$ patients}

The information obtained in this study provides important implications from the perspective of primary and secondary prevention of ischemic stroke in patients undergoing PCI. In our analysis, $97.4 \%$ of Japanese patients undergoing PCI had one or more risk factors for ischemic stroke, indicating that patients undergoing PCI are also at high risk of ischemic stroke due to arteriosclerotic lesions.

The cumulative incidence of non-fatal ischemic stroke that we observed $(0.68 \%)$ was lower than that for reported ischemic stroke in prior studies, such as PRASTRO-I
(3.1-4.6\%) [19] and CHANCE (10.2\%) [20]. However, these studies did not differentiate between fatal and non-fatal stroke, as fatal ischemic stroke is generally a rare event; thus, these comparisons should be interpreted with care. Of note, those studies evaluated stroke recurrence rates in patients with ischemic stroke, suggesting that their study populations might be at a higher risk of ischemic stroke compared with the patients included in our study. In support of this, the current analysis found a higher incidence of ischemic stroke in patients with a history of ischemic stroke than in the overall population. This is in line with the STOPDAPT-2 randomized clinical trial, in which the rate of ischemic stroke 
Table 2 Incidence of stroke (overall and by subtype) according to patient characteristics

\begin{tabular}{|c|c|c|c|c|c|c|c|c|c|}
\hline & \multirow[t]{3}{*}{$N$} & \multirow[t]{3}{*}{ All } & \multicolumn{6}{|c|}{ Ischemic stroke } & \multirow{3}{*}{$\begin{array}{l}\text { Non- } \\
\text { ischemic } \\
\text { stroke }\end{array}$} \\
\hline & & & \multirow[t]{2}{*}{ All } & \multicolumn{3}{|c|}{ Non-cardiogenic } & \multirow[t]{2}{*}{ Cardiogenic } & \multirow[t]{2}{*}{ Other } & \\
\hline & & & & All & Atherothrombotic & Lacunar & & & \\
\hline All & 6267 & $51(0.8)$ & $40(0.6)$ & $20(0.3)$ & $12(0.2)$ & $8(0.1)$ & $7(0.1)$ & $13(0.2)$ & $11(0.2)$ \\
\hline \multicolumn{10}{|l|}{ Age, years } \\
\hline$\geq 75$ & 2324 & $23(1.0)$ & $20(0.9)$ & $12(0.5)$ & $7(0.3)$ & $5(0.2)$ & $2(0.1)$ & $6(0.3)$ & $3(0.1)$ \\
\hline$<75$ & 3943 & $28(0.7)$ & $20(0.5)$ & $8(0.2)$ & $5(0.1)$ & $3(0.1)$ & $5(0.1)$ & $7(0.2)$ & $8(0.2)$ \\
\hline \multicolumn{10}{|l|}{ Sex } \\
\hline Male & 4909 & $42(0.9)$ & $31(0.6)$ & $15(0.3)$ & $8(0.2)$ & $7(0.1)$ & $6(0.1)$ & $10(0.2)$ & $11(0.2)$ \\
\hline Female & 1358 & $9(0.7)$ & $9(0.7)$ & $5(0.4)$ & $4(0.3)$ & $1(0.1)$ & $1(0.1)$ & $3(0.2)$ & 0 \\
\hline \multicolumn{10}{|l|}{ Body weight, $\mathrm{kg}$} \\
\hline$\leq 50$ & 794 & $9(1.1)$ & $9(1.1)$ & $5(0.6)$ & $4(0.5)$ & $1(0.1)$ & 0 & $4(0.5)$ & 0 \\
\hline$>50$ & 5326 & $41(0.8)$ & $30(0.6)$ & $14(0.3)$ & $7(0.1)$ & $7(0.1)$ & $7(0.1)$ & $9(0.2)$ & $11(0.2)$ \\
\hline \multicolumn{10}{|l|}{ Smoking } \\
\hline Yes & 1674 & $13(0.8)$ & $9(0.5)$ & $5(0.3)$ & $3(0.2)$ & $2(0.1)$ & 0 & $4(0.2)$ & $4(0.2)$ \\
\hline No & 3951 & $29(0.7)$ & $22(0.6)$ & $10(0.3)$ & $6(0.2)$ & $4(0.1)$ & $6(0.2)$ & $6(0.2)$ & $7(0.2)$ \\
\hline \multicolumn{10}{|l|}{ Hypertension } \\
\hline Yes & 5186 & $44(0.8)$ & $36(0.7)$ & $19(0.4)$ & $11(0.2)$ & $8(0.2)$ & $7(0.1)$ & $10(0.2)$ & $8(0.2)$ \\
\hline No & 1081 & $7(0.6)$ & $4(0.4)$ & $1(0.1)$ & $1(0.1)$ & 0 & 0 & $3(0.3)$ & $3(0.3)$ \\
\hline \multicolumn{10}{|l|}{ Hyperlipidemia } \\
\hline Yes & 4919 & $42(0.9)$ & $34(0.7)$ & $17(0.3)$ & $10(0.2)$ & $7(0.1)$ & $6(0.1)$ & $11(0.2)$ & $8(0.2)$ \\
\hline No & 1348 & $9(0.7)$ & $6(0.4)$ & $3(0.2)$ & $2(0.1)$ & $1(0.1)$ & $1(0.1)$ & $2(0.1)$ & $3(0.2)$ \\
\hline \multicolumn{10}{|l|}{ Diabetes mellitus } \\
\hline Yes & 2767 & $23(0.8)$ & $18(0.7)$ & $8(0.3)$ & $5(0.2)$ & $3(0.1)$ & $4(0.1)$ & $6(0.2)$ & $5(0.2)$ \\
\hline No & 3500 & $28(0.8)$ & $22(0.6)$ & $12(0.3)$ & $7(0.2)$ & $5(0.1)$ & $3(0.1)$ & $7(0.2)$ & $6(0.2)$ \\
\hline \multicolumn{10}{|l|}{$\mathrm{eGFR}, \mathrm{mL} / \mathrm{min} / 1.73 \mathrm{~m}^{2}$} \\
\hline$<30$ & 598 & $6(1.0)$ & $6(1.0)$ & $3(0.5)$ & $1(0.2)$ & $2(0.3)$ & $2(0.3)$ & $1(0.2)$ & 0 \\
\hline$\geq 30$ to $<60$ & 2093 & $16(0.8)$ & $12(0.6)$ & $6(0.3)$ & $3(0.1)$ & $3(0.1)$ & 0 & $6(0.3)$ & $4(0.2)$ \\
\hline$\geq 60$ & 3431 & $27(0.8)$ & $20(0.6)$ & $9(0.3)$ & $6(0.2)$ & $3(0.1)$ & $5(0.1)$ & $6(0.2)$ & $7(0.2)$ \\
\hline \multicolumn{10}{|l|}{ Anemia, hemoglobin $\mathrm{g} / \mathrm{dL}$} \\
\hline$<11$ & 727 & $8(1.1)$ & $7(1.0)$ & $4(0.6)$ & $1(0.1)$ & $3(0.4)$ & 0 & $3(0.4)$ & $1(0.1)$ \\
\hline $\begin{array}{l}\geq 11 \text { to }<13 \text { (male) or } \geq 11 \\
\text { to }<12 \text { (female) }\end{array}$ & 1414 & $13(0.9)$ & $10(0.7)$ & $5(0.4)$ & $4(0.3)$ & $1(0.1)$ & $2(0.1)$ & $3(0.2)$ & $3(0.2)$ \\
\hline$\geq 13$ (male) or $\geq 12$ (female) & 3946 & $27(0.7)$ & $20(0.5)$ & $8(0.2)$ & $5(0.1)$ & $3(0.1)$ & $5(0.1)$ & $7(0.2)$ & $7(0.2)$ \\
\hline \multicolumn{10}{|c|}{ PRU value at $12-48 \mathrm{~h}$ after index PCI } \\
\hline HPR (> 208) & 2227 & $20(0.9)$ & $17(0.8)$ & $9(0.4)$ & $6(0.3)$ & $3(0.1)$ & $2(0.1)$ & $6(0.3)$ & $3(0.1)$ \\
\hline OPR $(>85$ to $\leq 208)$ & 3002 & $23(0.8)$ & $18(0.6)$ & $9(0.3)$ & $4(0.1)$ & $5(0.2)$ & $4(0.1)$ & $5(0.2)$ & $5(0.2)$ \\
\hline LPR $(\leq 85)$ & 677 & $4(0.6)$ & $2(0.3)$ & $1(0.1)$ & $1(0.1)$ & 0 & $1(0.1)$ & 0 & $2(0.3)$ \\
\hline \multicolumn{10}{|l|}{ Cardiovascular status } \\
\hline \multicolumn{10}{|l|}{ ACS } \\
\hline Yes & 2015 & $22(1.1)$ & $19(0.9)$ & $9(0.4)$ & $6(0.3)$ & $3(0.1)$ & $3(0.1)$ & $7(0.3)$ & $3(0.1)$ \\
\hline No & 4252 & $29(0.7)$ & $21(0.5)$ & $11(0.3)$ & $6(0.1)$ & $5(0.1)$ & $4(0.1)$ & $6(0.1)$ & $8(0.2)$ \\
\hline PAD & & & & & & & & & \\
\hline Yes & 421 & $3(0.7)$ & $3(0.7)$ & $1(0.2)$ & $1(0.2)$ & 0 & 0 & $2(0.5)$ & 0 \\
\hline No & 5846 & $48(0.8)$ & $37(0.6)$ & $19(0.3)$ & $11(0.2)$ & $8(0.1)$ & $7(0.1)$ & $11(0.2)$ & $11(0.2)$ \\
\hline Heart failure & & & & & & & & & \\
\hline Yes & 850 & $9(1.1)$ & $8(0.9)$ & $4(0.5)$ & $2(0.2)$ & $2(0.2)$ & 0 & $4(0.5)$ & $1(0.1)$ \\
\hline No & 5417 & $42(0.8)$ & $32(0.6)$ & $16(0.3)$ & $10(0.2)$ & $6(0.1)$ & $7(0.1)$ & $9(0.2)$ & $10(0.2)$ \\
\hline $\mathrm{AF}$ & & & & & & & & & \\
\hline Yes & 538 & $10(1.9)$ & $8(1.5)$ & $5(0.9)$ & $3(0.6)$ & $2(0.4)$ & $2(0.4)$ & $1(0.2)$ & $2(0.4)$ \\
\hline
\end{tabular}


Table 2 (continued)

\begin{tabular}{|c|c|c|c|c|c|c|c|c|c|}
\hline & \multirow[t]{3}{*}{$N$} & \multirow[t]{3}{*}{ All } & \multicolumn{6}{|c|}{ Ischemic stroke } & \multirow{3}{*}{$\begin{array}{l}\text { Non- } \\
\text { ischemic } \\
\text { stroke }\end{array}$} \\
\hline & & & \multirow[t]{2}{*}{ All } & \multicolumn{3}{|c|}{ Non-cardiogenic } & \multirow[t]{2}{*}{ Cardiogenic } & \multirow[t]{2}{*}{ Other } & \\
\hline & & & & All & Atherothrombotic & Lacunar & & & \\
\hline No & 5729 & $41(0.7)$ & $32(0.6)$ & $15(0.3)$ & $9(0.2)$ & $6(0.1)$ & $5(0.1)$ & $12(0.2)$ & $9(0.2)$ \\
\hline \multicolumn{10}{|c|}{ Medical history } \\
\hline \multicolumn{10}{|l|}{ MI } \\
\hline Yes & 1575 & $11(0.7)$ & $8(0.5)$ & $6(0.4)$ & $3(0.2)$ & $3(0.2)$ & 0 & $2(0.1)$ & $3(0.2)$ \\
\hline No & 4661 & $40(0.9)$ & $32(0.7)$ & $14(0.3)$ & $9(0.2)$ & $5(0.1)$ & $7(0.2)$ & $11(0.2)$ & $8(0.2)$ \\
\hline \multicolumn{10}{|c|}{ Stroke } \\
\hline Yes & 741 & $11(1.5)$ & $9(1.2)$ & $5(0.7)$ & $3(0.4)$ & $2(0.3)$ & 0 & $4(0.5)$ & $2(0.3)$ \\
\hline No & 5308 & $35(0.7)$ & $28(0.5)$ & $13(0.2)$ & $7(0.1)$ & $6(0.1)$ & $7(0.1)$ & $8(0.2)$ & $7(0.1)$ \\
\hline \multicolumn{10}{|c|}{ Hemorrhagic stroke } \\
\hline Yes & 124 & $1(0.8)$ & 0 & 0 & 0 & 0 & 0 & 0 & $1(0.8)$ \\
\hline No & 5892 & $44(0.7)$ & $36(0.6)$ & $17(0.3)$ & $10(0.2)$ & $7(0.1)$ & $7(0.1)$ & $12(0.2)$ & $8(0.1)$ \\
\hline \multicolumn{10}{|c|}{ Ischemic stroke } \\
\hline Yes & 655 & $11(1.7)$ & $9(1.4)$ & $5(0.8)$ & $3(0.5)$ & $2(0.3)$ & 0 & $4(0.6)$ & $2(0.3)$ \\
\hline No & 5396 & $35(0.6)$ & $28(0.5)$ & $13(0.2)$ & $7(0.1)$ & $6(0.1)$ & $7(0.1)$ & $8(0.1)$ & $7(0.1)$ \\
\hline \multicolumn{10}{|c|}{ Risk factor for ischemic stroke ${ }^{a}$} \\
\hline Yes & 6102 & $51(0.8)$ & $40(0.7)$ & $20(0.3)$ & $12(0.2)$ & $8(0.1)$ & $7(0.1)$ & $13(0.2)$ & $11(0.2)$ \\
\hline No & 165 & 0 & 0 & 0 & 0 & 0 & 0 & 0 & 0 \\
\hline \multicolumn{10}{|c|}{$\mathrm{OAC}$ at discharge } \\
\hline Yes & 610 & $8(1.3)$ & $5(0.8)$ & $1(0.2)$ & 0 & $1(0.2)$ & $2(0.3)$ & $2(0.3)$ & $3(0.5)$ \\
\hline No & 5657 & $43(0.8)$ & $35(0.6)$ & $19(0.3)$ & $12(0.2)$ & $7(0.1)$ & $5(0.1)$ & $11(0.2)$ & $8(0.1)$ \\
\hline
\end{tabular}

Data are $N$ or $n(\%)$

$A C S$ acute coronary syndrome, $A F$ atrial fibrillation, $e G F R$ estimated glomerular filtration rate, $H P R$ high $\mathrm{P} 2 \mathrm{Y}_{12}$ reaction unit value, $L P R$ low $\mathrm{P}_{2} \mathrm{Y}_{12}$ reaction unit value, $M I$ myocardial infarction, NSAID non-steroidal anti-inflammatory drug, $O A C$ oral anticoagulant, $O P R$ optimal $\mathrm{P} 2 \mathrm{Y}_{12}$ reaction unit value, $P A D$ peripheral artery disease, $P R U \mathrm{P}_{2} \mathrm{Y}_{12}$ reaction unit

${ }^{a}$ History of ischemic stroke, diabetes, hyperlipidemia, eGFR $<60 \mathrm{~mL} / \mathrm{min} / 1.73 \mathrm{~m}^{2}$, or hypertension

Fig. 4 Cumulative incidence of non-fatal ischemic stroke at 12 months after the first PCI according to $\mathrm{P} 2 \mathrm{Y}_{12}$ reaction unit value $12-48 \mathrm{~h}$ after the first PCI $(\leq 153$ versus $>153)$. CI confidence interval, $H R$ hazard ratio, $P C I$ percutaneous coronary intervention, $P R U \mathrm{P}_{2} \mathrm{Y}_{12}$ reaction unit

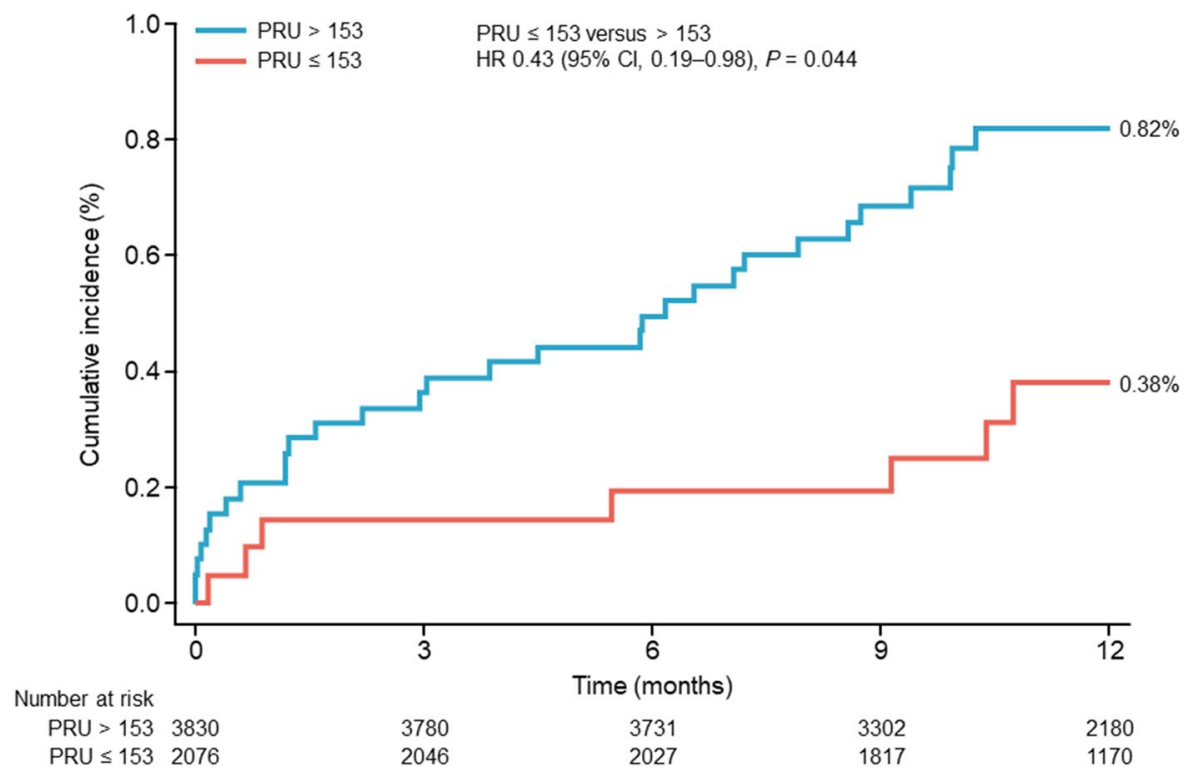


at 1 year was $1.03 \%$ in patients who received 12 months of DAPT treatment [21].

Based on current Japanese guidelines, DAPT for preventing ischemic stroke recurrence should generally be restricted to a maximum of 3 months, with a short period of 3 weeks most commonly employed [3]. However, at the time of the PENDULUM study, it was recommended that DAPT be continued for at least 12 months to prevent stent thrombosis in PCI patients [3], and approximately $80 \%$ of PENDULUM patients continued DAPT treatment for 12 months. As a result, our data may reflect the outcomes of long-term DAPT in patients with ischemic heart disease. Our findings suggest that long-term continuation of DAPT may have benefits that override the adverse effects of DAPT among patients undergoing PCI.

Improved risk management for PCI patients may also have resulted in lower stroke rates in our analysis. While $82.8 \%$ of PENDULUM patients had a history of hypertension at baseline [17], optimal medical treatment was adopted. In addition, there were high prescription rates of dyslipidemia drugs and antidiabetic drugs, further controlling potential stroke risks.

\section{Association between non-fatal ischemic stroke and PRU after PCI}

Although PRU values at $12-48 \mathrm{~h}$ post-PCI do not always match the PRU at the time of onset of ischemic stroke, many patients continued to use antiplatelet drugs at 12 months in this study. Most patients with non-fatal ischemic stroke events were taking P2 $\mathrm{Y}_{12}$ inhibitors at the time of the event. Thus, we considered that PRU at 12-48 h after PCI was an appropriate marker to reflect the platelet aggregation ability at the time of ischemic stroke for patients in the PENDULUM registry.

The observation that patients with ischemic stroke events had significantly higher mean PRUs than those without events suggests that high PRU levels may be a risk factor for ischemic stroke. The trend towards a higher 1-year cumulative incidence in patients with HPR and a lower incidence in those with LPR supports this hypothesis. However, the differences between groups were not statistically significantly different, likely due to insufficient power because of the small numbers of events. In addition, the results of our previous report, in which the cardiovascular composite endpoint was an independent risk factor after adjusting for PRU, may also support the association between ischemic risk and PRU [17], as do the findings of a meta-analysis in which HPR at the time of $\mathrm{P} 2 \mathrm{Y}_{12}$ inhibitor administration was shown to increase ischemic risk [11].

To date, evidence are lacking to suggest an association between HPR and stroke, and no cutoffs have been reported. In the open-label PRINCE trial of ticagrelor plus aspirin versus clopidogrel plus aspirin, HPR was associated with clinical outcomes for patients [22]. In addition, the PRINCE trial reported that the administration of clopidogrel significantly increased the risk of subsequent stroke compared with ticagrelor in patients who had an atherothrombotic stroke; furthermore, non-cardiogenic stroke, especially atherothrombotic ischemic stroke, tended to have a higher event incidence in patients with HPR compared with LPR [22]. There is no established cutoff PRU value for preventing ischemic stroke in patients undergoing PCI. Thus, we used the prespecified cutoff value (PRU $>208$ ) to prevent cardiovascular events in patients undergoing PCI applied in the ADAPT-DES study [14] as reference. In this study, the calculated PRU cutoff for the onset of non-fatal ischemic stroke was 153; this is lower than the optimum PRU cutoff value of 206 for definite-probable and definite stent thrombosis calculated by ROC analysis in the ADAPT-DES study [14]. Although the discriminatory power for any event was poor or moderate, we can hypothesize that lowering the platelet aggregation ability is important for preventing ischemic stroke after PCI. However, this hypothesis requires further confirmation. Although the PRU cutoff value for the onset of non-fatal ischemic stroke was 153 , the risk of non-fatal ischemic stroke was 0.43 , which is consistent with a previous report [11].

\section{Non-fatal non-ischemic stroke}

It is known that East Asians, including Japanese individuals, are more prone to cerebral hemorrhage than other ethnicities [23]. However, the cumulative incidence of non-fatal nonischemic stroke $(0.18 \%)$ in this analysis was low.

In the main PENDULUM analysis, few Japanese patients had excessively reduced platelet aggregation (LPR) while receiving $\mathrm{P}_{2} \mathrm{Y}_{12}$ treatment [17]. Therefore, although an inverse association between bleeding and PRU was reported in the ADAPT-DES study [14], no such relationship was observed in the PENDULUM population.

There are several possible reasons why PRU levels in Japanese patients may be reduced to a lesser extent than the European and US patients in the ADAPT-DES study. These include the impact of CYP2C19 polymorphism on clopidogrel $[24,25]$, and a higher proportion of poor metabolizers and a lower proportion of ultra-rapid metabolizers in Japan compared with other countries [26, 27]. Moreover, prasugrel is less susceptible to CYP2C19 variation, and, as a result, its efficacy is more stable across patient populations [28]. Of note, in Japan, approximately one-third of prasugrel prescriptions consist of low-dose prescriptions, meaning that the PRU levels in patients receiving low-dose prasugrel are reduced to the same extent as the levels observed in clopidogrel extensive metabolizers [29]. These hypotheses remain to be validated in future studies, and clinical analyses 
to evaluate the impact of long-term DAPT on the onset of a cerebral hemorrhage are warranted.

\section{Limitations}

The main limitation of these data is the post hoc nature of the analysis; as the number of stroke events was small, statistical significance calculations were likely underpowered. Moreover, it is difficult to conduct some verifying analyses due to the small number of events. In addition, PRU was measured at $12-48 \mathrm{~h}$ after PCI and its level may have altered with medication changes during the observation period. However, because most of the patients who developed cerebral infarction continued DAPT, it is assumed that the PRU of patients who developed events was similar to that of $12-48 \mathrm{~h}$ after PCI. Nonetheless, the association between PRU and ischemic events observed in this analysis was consistent with the previously reported results of the PENDULUM registry [17]. We consider that these exploratory data provide important information for clinicians.

The exclusion of fatal strokes is another important limitation, meaning that data on severe strokes are still lacking. As most fatal strokes are due to cerebral hemorrhage [30], the results of this study may have underestimated outcomes related to ischemic stroke. However, as the proportion of fatal strokes in the PENDULUM study was low (data not shown), the influence of stroke mortality on the data reported herein is expected to be small.

In this study, the use of $\mathrm{P}_{2} \mathrm{Y}_{12}$ inhibitors was determined at the physician's discretion, and the degree of platelet coagulation inhibition may vary depending on the type of drug administered. However, we consider that by evaluating PRU, an index of drug efficacy, we provided strong evidence for the links between platelet aggregation capability and stroke, regardless of the treatment regimen administered. Finally, the PENDULUM registry only included Japanese patients, which limits the generalizability of the findings. It is unclear whether our PRU cutoff is optimal for a secondary prevention trial of stroke.

\section{Conclusion}

We have demonstrated that the cumulative stroke incidence 12 months post-PCI in Japanese patients was $0.68 \%$ for ischemic stroke and $0.18 \%$ for non-ischemic stroke, and that high PRU values at $12-48 \mathrm{~h}$ after PCI were associated with increased rates of ischemic stroke.

Supplementary Information The online version contains supplementary material available at https://doi.org/10.1007/s00380-021-02003-w.
Acknowledgements We thank Sally-Anne Mitchell, PhD, of Edanz (www.edanz.com) for providing medical writing support, which was funded by Daiichi Sankyo Co., Ltd.

Author contributions All the authors provided substantial contributions to the conception or design of the work, or the acquisition, analysis, or interpretation of data for the work; participated in drafting the work or revising it critically for important intellectual content; provided final approval of the version to be published; and are in agreement to be accountable for all aspects of the work in ensuring that questions related to the accuracy or integrity of any part of the work are appropriately investigated and resolved.

Funding This work was supported by Daiichi Sankyo Co., Ltd. Daiichi Sankyo Co., Ltd. played a role in the design and conduct of the study; collection, management, and interpretation of the data; preparation, review, and approval of the manuscript; and the decision to submit the manuscript for publication.

Data availability The deidentified participant data and the study protocol will be shared on a request basis for up to 36 months after the publication of this article. Researchers who make the request should include a methodologically sound proposal on how the data will be used; the proposal may be reviewed by the responsible personnel at Daiichi Sankyo Co., Ltd., and the data requestors will need to sign a data access agreement. Please directly contact the corresponding author to request data sharing. Once approved, the data will be shared in an appropriate way depending on the type of data requested.

\section{Declarations}

Conflict of interest Y. Matsumaru has received remuneration from Daiichi Sakyo Co., Ltd., and Otsuka Pharmaceutical Co., Ltd. T. Kitazono has received remuneration and scholarship funds or donations from Daiichi Sakyo Co., Ltd. K. Kadota has received remuneration from Daiichi Sankyo Co., Ltd., and Sanofi K.K. K. Nakao has received remuneration from Daiichi Sankyo Co., Ltd. Y. Nakagawa has received remuneration from Bristol Myers Squibb K.K., Kowa Pharmaceutical Co., Ltd., Daiichi Sankyo Co., Ltd., Bayer Yakuhin Ltd., Sanofi K.K., Boston Scientific Corporation, and Abbott Medical Japan LLC., and research funding from Daiichi Sankyo Co., Ltd., Bayer Yakuhin Ltd., Sanofi K.K., Boston Scientific Corporation, and Abbott Medical Japan LLC. J. Shite has received remuneration from Daiichi Sankyo Co., Ltd., Nipro Corporation, Abbott Japan LLC, and Terumo Corporation. H. Yokoi has received remuneration and scholarship funds or donations from Daiichi Sankyo Co., Ltd. K. Kozuma has received remuneration and research funding from Daiichi Sankyo Co., Ltd. K. Tanabe has received remuneration from Daiichi Sankyo Co., Ltd., Sanofi K.K., AstraZeneca K.K., Abbott Medical Japan LLC., Boston Scientific Corporation, and Terumo Corporation. T. Akasaka has received remuneration from Abbot Medical Japan LLC., and Otsuka Pharmaceutical Co., Ltd., research funding from Daiichi Sankyo Co., Ltd., scholarship funds or donations from Abbot Medical Japan LLC., Nipro Corporation, and Terumo Corporation, and has a personal relationship with Terumo Corporation. T. Shinke has received remuneration and research funding from Daiichi Sankyo Co., Ltd., Bayer Yakuhin Ltd., Bristol Myers Squibb K.K., and Nippon Boehringer Ingelheim Co., Ltd. T. Ueno received consultancy fees from Japan Medical Device Technology Co., Ltd., and Nipro Corporation. A. Hirayama has received remuneration from Daiichi Sankyo Co., Ltd., Bayer Yakuhin Ltd., and Takeda Pharmaceutical Co., Ltd. S. Uemura has received remuneration from Daiichi Sankyo Co., Ltd., Nippon Boehringer Ingelheim Co., Ltd., Amgen Astellas BioPharma Co., Ltd., Abbot Medical Japan LLC., Sanofi K.K., Terumo Corporation, and Bayer 
Yakuhin Ltd.; and research funding from Daiichi Sankyo Co., Ltd.; and scholarship funds or donations from Daiichi Sankyo Co., Ltd., Astellas Pharma Inc., Otsuka Pharmaceutical Co., Ltd., Goodman Co., Ltd., Shionogi Inc., Sumitomo Dainippon Pharma Co., Ltd., Boston Scientific Japan K.K., Kaken Pharmaceutical Co., Ltd., Takeda Pharmaceutical Co., Ltd., Taisho Pharmaceutical Co., Ltd., Mitsubishi Tanabe Pharmaceutical Co., Ltd., Japan Lifeline Co., Ltd., MSD K.K., Nipro Corporation, Actelion Pharmaceuticals Japan Ltd., Pfizer Japan Inc., Abbot Medical Japan LLC., Sanofi K.K., Terumo Corporation, and Bayer Yakuhin Ltd. T. Kuroda, A. Takita, and A. Harada, are employees of Daiichi Sankyo Co., Ltd. Y. Murakami has received remuneration from SRD Co., Ltd. S. Saito has received consultancy fees from Japan Lifeline Inc., and Terumo Corporation; and remuneration from Daiichi Sankyo Co., Ltd, Abbott Medical Japan LLC., Boston Scientific Corporation, and Medtronic Japan Co., Ltd. M. Nakamura has received remuneration from Daiichi Sankyo Co., Ltd., Sanofi K.K., Terumo Corporation, and Bristol Myers Squibb K.K, and research funding from Daiichi Sankyo Co., Ltd., Sanofi K.K., and Bayer Yakuhin K.K. R. Iijima has no conflicts of interest to declare.

Ethics approval The study was performed per the principles of the Declaration of Helsinki and the Ethical Guidelines for Medical and Health Research Involving Human Subjects and was registered in the University hospital Medical Information Network (UMIN) Clinical Trial Registry (UMIN 000020332). The study protocol and related documents were approved by the Ethics Committee at Toho University Ohashi Medical Center on 14 December 2015 (reference code: 15-71).

Consent to participate All patients provided written informed consent before study participation.

Open Access This article is licensed under a Creative Commons Attribution 4.0 International License, which permits use, sharing, adaptation, distribution and reproduction in any medium or format, as long as you give appropriate credit to the original author(s) and the source, provide a link to the Creative Commons licence, and indicate if changes were made. The images or other third party material in this article are included in the article's Creative Commons licence, unless indicated otherwise in a credit line to the material. If material is not included in the article's Creative Commons licence and your intended use is not permitted by statutory regulation or exceeds the permitted use, you will need to obtain permission directly from the copyright holder. To view a copy of this licence, visit http://creativecommons.org/licenses/by/4.0/.

\section{References}

1. GBD 2016 Stroke Collaborators (2019) Global, regional, and national burden of stroke, 1990-2016: a systematic analysis for the Global Burden of Disease Study 2016. Lancet Neurol $18: 439-458$

2. Venketasubramanian N, Yoon BW, Pandian J, Navarro JC (2017) Stroke epidemiology in South, East, and South-East Asia: a review. J Stroke 19:286-294

3. Ishihara H, Suzuki M (2016) Japanese guidelines for the management of stroke 2015: overview of the chapter on subarachnoid hemorrhage. Nihon Rinsho 74:677-680

4. Kargiotis O, Tsivgoulis G (2021) The 2020 breakthroughs in early secondary prevention: dual antiplatelet therapy versus single antiplatelet therapy. Curr Opin Neurol 34:45-54

5. Wang Y, Wang Y, Zhao X, Liu L, Wang D, Wang C, Li H, Meng X, Cui L, Jia J, Dong Q, Xu A, Zeng J, Li Y, Wang Z, Xia H, Johnston SC, CHANCE Investigators (2013) Clopidogrel with aspirin in acute minor stroke or transient ischemic attack. N Engl J Med 369:11-19

6. Johnston SC, Easton JD, Farrant M, Barsan W, Conwit RA, Elm JJ, Kim AS, Lindblad AS, Palesch YY, Clinical Research Collaboration, Neurological Emergencies Treatment Trials Network, and the POINT Investigators (2018) Clopidogrel and aspirin in acute ischemic stroke and high-risk TIA. N Engl J Med 379:215-225

7. Wiśniewski A, Filipska K (2020) The phenomenon of clopidogrel high on-treatment platelet reactivity in ischemic stroke subjects: a comprehensive review. Int J Mol Sci 21:6408

8. Mangieri A, Gallo F, Sticchi A, Khokhar AA, Laricchia A, Giannini F, Colombo A (2020) Dual antiplatelet therapy in coronary artery disease: from the past to the future prospective. Cardiovasc Interv Ther 35:117-129

9. Alakbarzade V, Huang X, Ster IC, McEntagart M, Pereira AC (2020) High on-clopidogrel platelet reactivity in ischaemic stroke or transient ischaemic attack: systematic review and meta-analysis. J Stroke Cerebrovasc Dis 29:104877

10. Fiolaki A, Katsanos AH, Kyritsis AP, Papadaki S, Kosmidou M, Moschonas IC, Tselepis AD, Giannopoulos S (2017) High on treatment platelet reactivity to aspirin and clopidogrel in ischemic stroke: a systematic review and meta-analysis. J Neurol Sci 376:112-116

11. Lim ST, Thijs V, Murphy SJX, Fernandez-Cadenas I, Montaner J, Offiah C, Marquardt L, Kelly PJ, Bath PM, Lim S-Y, Ford GA, Norrving B, Cox D, Prodan CI, Barber PA, Werring DJ, Perry R, Zgaga L, Dawson J, McCabe DJH (2020) Platelet function/reactivity testing and prediction of risk of recurrent vascular events and outcomes after TIA or ischaemic stroke: systematic review and meta-analysis. J Neurol 267:3021-3037

12. Collet JP, Thiele H, Barbato E, Barthelemy O, Bauersachs J, Bhatt DL, Dendale P, Dorobantu M, Edvardsen T, Folliguet T, Gale CP, Gilard M, Jobs A, Jüni P, Lambrinou E, Lewis BS, Mehilli J, Meliga E, Merkely B, Mueller C, Roffi M, Rutten FH, Sibbing D, Siontis GCM, ESC Scientific Document Group (2021) 2020 ESC guidelines for the management of acute coronary syndromes in patients presenting without persistent ST-segment elevation. Eur Heart J 42:1289-1367

13. Nakamura M, Kimura K, Kimura T, Ishihara M, Otsuka F, Kozuma K, Kosuge M, Shinke T, Nakagawa Y, Natsuaki M, Yasuda S, Akasaka T, Kohsaka S, Haze K, Hirayama A (2020) JCS 2020 guideline focused update on antithrombotic therapy in patients with coronary artery disease. Circ J 84:831-865

14. Stone GW, Witzenbichler B, Weisz G, Rinaldi MJ, Neumann FJ, Metzger DC, Henry TD, Cox DA, Duffy PL, Mazzaferri E, Gurbel PA, Xu K, Parise H, Kirtane AJ, Brodie BR, Mehran R, Stuckey TD, ADAPT-DES Investigators (2013) Platelet reactivity and clinical outcomes after coronary artery implantation of drugeluting stents (ADAPT-DES): a prospective multicentre registry study. Lancet 382:614-623

15. Sibbing D, Aradi D, Alexopoulos D, Ten Berg J, Bhatt DL, Bonello L, Collet J-P, Cuisset T, Franchi F, Gross L, Gurbel P, Jeong Y-H, Mehran R, Moliterno DJ, Neumann F-J, Pereira NL, Price MJ, Sabatine MS, So DYF, Stone GW, Storey RF, Tantry U, Trenk D, Valgimigli M, Waksman R, Angiolillo DJ (2019) Updated expert consensus statement on platelet function and genetic testing for guiding $\mathrm{P} 2 \mathrm{Y}_{12}$ receptor inhibitor treatment in percutaneous coronary intervention. JACC Cardiovasc Interv 12:1521-1537

16. Urban P, Mehran R, Colleran R, Angiolillo DJ, Byrne RA, Capodanno D, Cuisset T, Cutlip D, Eerdmans P, Eikelboom J, Farb A, Gibson CM, Gregson J, Haude M, James SK, Kim H-S, Kimura T, Konishi A, Laschinger J, Leon MB, Magee PFA, Mitsutake Y, Mylotte D, Pocock S, Price MJ, Rao SV, Spitzer E, Stockbridge N, Valgimigli M, Varenne O, Windhoevel U, Yeh RW, Krucoff MW, Morice MC (2019) Defining high bleeding risk in patients 
undergoing percutaneous coronary intervention: a consensus document from the academic research consortium for high bleeding risk. Eur Heart J 40:2632-2653

17. Nakamura M, Kadota K, Takahashi A, Kanda J, Anzai H, Ishii Y, Shibata Y, Yasaka Y, Takamisawa I, Yamaguchi J, Takeda Y, Harada A, Motohashi T, Iijima R, Uemura S, Murakami Y, for the PENDULUM Registry Investigators (2020) Relationship between platelet reactivity and ischemic and bleeding events after percutaneous coronary intervention in East Asian patients: 1-year results of the PENDULUM registry. J Am Heart Assoc 9:e015439

18. Yi HJ, Hwang G, Lee BH (2019) Variability of platelet reactivity on antiplatelet therapy in neurointervention procedure. J Korean Neurosurg Soc 62:3-9

19. Kitazono T, Toyoda K, Kitagawa K, Nagao T, Yamagami H, Uchiyama S, Tanahashi N, Matsumoto M, Minematsu K, Nagata I, Nishikawa M, Nanto S, Ikeda Y, Shirai T, Abe K, Ogawa A, PRASTRO-I Study Group (2021) Efficacy and safety of prasugrel by stroke subtype: a sub-analysis of the PRASTRO-I randomized controlled trial. J Atheroscler Thromb 28:169-180

20. Wang Y, Pan Y, Zhao X, Li H, Wang D, Johnston SC, Liu L, Meng X, Wang A, Wang C, Wang Y, CHANCE Investigators (2015) Clopidogrel with aspirin in acute minor stroke or transient ischemic attack (CHANCE) trial: one-year outcomes. Circulation 132:40-46

21. Watanabe H, Domei T, Morimoto T, Natsuaki M, Shiomi H, Toyota T, Ohya M, Suwa S, Takagi K, Nanasato M, Hata Y, Yagi M, Suematsu N, Yokomatsu T, Takamisawa I, Doi M, Noda T, Okayama H, Seino Y, Tada T, Sakamoto H, Hibi K, Abe M, Kawai K, Nakao K, Ando K, Tanabe K, Ikari Y, Hanaoka KI, Morino Y, Kozuma K, Kadota K, Furukawa Y, Nakagawa Y, Kimura K, STOPDAPT-2 Investigators (2019) Effect of 1-month dual antiplatelet therapy followed by clopidogrel vs 12 -month dual antiplatelet therapy on cardiovascular and bleeding events in patients receiving PCI: The STOPDAPT-2 randomized clinical trial. JAMA 321:2414-2427

22. Wang Y, Chen W, Lin Y, Meng X, Chen G, Wang Z, Wu J, Wang D, Li J, Cao Y, Xu Y, Zhang G, Li X, Pan Y, Li H, Zhao X, Liu L, Lin J, Dong K, Jing J, Johnston SC, Wang D, Wang Y, PRINCE Protocol Steering Group (2019) Ticagrelor plus aspirin versus clopidogrel plus aspirin for platelet reactivity in patients with minor stroke or transient ischaemic attack: Open label, blinded endpoint, randomised controlled phase II trial. BMJ 365:12211

23. Khan NA, Quan H, Hill MD, Pilote L, McAlister FA, Palepu A, Shah BR, Zhou L, Zhen H, Kapral MK (2013) Risk factors, quality of care and prognosis in South Asian, East Asian and White patients with stroke. BMC Neurol 13:74

24. Pan Y, Chen W, Xu Y, Yi X, Han Y, Yang Q, Li X, Huang L, Johnston SC, Zhao X, Liu L, Zhang Q, Wang G, Wang Y, Wang Y (2017) Genetic polymorphisms and clopidogrel efficacy for acute ischemic stroke or transient ischemic attack: a systematic review and meta-analysis. Circulation 135:21-33

25. Scott SA, Sangkuhl K, Gardner EE, Stein CM, Hulot JS, Johnson JA, Johnson JA, Roden DM, Klein TE, Shuldiner AR, Clinical Pharmacogenetics Implementation Consortium (2011) Clinical pharmacogenetics implementation consortium guidelines for cytochrome P450-2C19 (CYP2C19) genotype and clopidogrel therapy. Clin Pharmacol Ther 90:328-332

26. Amin AM, Sheau Chin L, Azri Mohamed Noor D, Sk Abdul Kader MA, Kah Hay Y, Ibrahim B (2017) The personalization of clopidogrel antiplatelet therapy: the role of integrative pharmacogenetics and pharmacometabolomics. Cardiol Res Pract 2017:8062796

27. Dorji PW, Tshering G, Na-Bangchang K (2019) CYP2C9, CYP2C19, CYP2D6 and CYP3A5 polymorphisms in South-East and East Asian populations: a systematic review. J Clin Pharm Ther 44:508-524

28. Isshiki T, Kimura T, Ogawa H, Yokoi H, Nanto S, Takayama M, Kitagawa K, Nishikawa M, Miyazaki S, Ikeda Y, Nakamura M, Saito S, on behalf of the PRASFIT-Elective Investigators (2014) Prasugrel, a third-generation $\mathrm{P}_{2} \mathrm{Y}_{12}$ receptor antagonist, in patients with coronary artery disease undergoing elective percutaneous coronary intervention. Circ J 78:2926-2934

29. Ogawa H, Isshiki T, Kimura T, Yokoi H, Nanto S, Takayama M, Kitagawa K, Nishikawa M, Miyazaki S, Ikeda Y, Nakamura M, Tanaka Y, Saito S (2016) Effects of CYP2C19 allelic variants on inhibition of platelet aggregation and major adverse cardiovascular events in Japanese patients with acute coronary syndrome: the PRASFIT-ACS study. J Cardiol 68:29-36

30. Krishnamurthi RV, Ikeda T, Feigin VL (2020) Global, regional and country-specific burden of ischaemic stroke, intracerebral haemorrhage and subarachnoid haemorrhage: A systematic analysis of the Global Burden of Disease study 2017. Neuroepidemiology $54: 171-179$

Publisher's Note Springer Nature remains neutral with regard to jurisdictional claims in published maps and institutional affiliations.

\section{Authors and Affiliations}

\section{Yuji Matsumaru ${ }^{1} \cdot$ Takanari Kitazono $^{2} \cdot$ Kazushige Kadota $^{3} \cdot$ Koichi Nakao $^{4} \cdot$ Yoshihisa Nakagawa $^{5} \cdot$ Junya Shite $^{6}$. Hiroyoshi Yokoi $^{7} \cdot$ Ken Kozuma $^{8} \cdot$ Kengo Tanabe $^{9} \cdot$ Takashi Akasaka $^{10} \cdot$ Toshiro Shinke $^{11} \cdot$ Takafumi Ueno $^{12}$. Atsushi Hirayama ${ }^{13}$. Shiro Uemura ${ }^{14} \cdot$ Takeshi Kuroda $^{15}$. Atsushi Takita ${ }^{16}$. Atsushi Harada ${ }^{17} \cdot$ Raisuke lijima $^{18}$. Yoshitaka Murakami ${ }^{19} \cdot$ Shigeru Saito $^{20} \cdot$ Masato Nakamura $^{18}$}

1 Division of Stroke Prevention and Treatment, Department of Neurosurgery, Faculty of Medicine, University of Tsukuba, 1-1-1 Tennodai, Tsukuba, Ibaraki 305-8575, Japan

2 Department of Clinical Medicine, National University Corporation Kyushu University, Fukuoka, Japan

3 Department of Cardiology, Kurashiki Central Hospital, Okayama, Japan
4 Division of Cardiology, Saiseikai Kumamoto Hospital Cardiovascular Center, Kumamoto, Japan

5 Department of Cardiovascular Medicine, Shiga University of Medical Science, Shiga, Japan

6 Division of Cardiology, Osaka Saiseikai Nakatsu Hospital, Osaka, Japan

7 Cardiovascular Medicine Center, Fukuoka Sanno Hospital, Fukuoka, Japan 
8 Division of Cardiology, Department of Internal Medicine, Teikyo University, Tokyo, Japan

9 Division of Cardiology, Mitsui Memorial Hospital, Tokyo, Japan

10 Department of Cardiovascular Medicine, Wakayama Medical University, Wakayama, Japan

11 Division of Cardiology, Department of Medicine, Showa University School of Medicine, Tokyo, Japan

12 Department of Cardiovascular Medicine, Fukuoka Kinen Hospital, Fukuoka, Japan

13 Department of Cardiology, Osaka Police Hospital, Osaka, Japan

14 Department of Cardiology, Kawasaki Medical School, Okayama, Japan
15 Medical Science Department, Daiichi Sankyo Co., Ltd., Tokyo, Japan

16 Data Intelligence Department, Daiichi Sankyo Co., Ltd., Tokyo, Japan

17 Medical Information Department, Daiichi Sankyo Co., Ltd., Tokyo, Japan

18 Division of Cardiovascular Medicine, Toho University Ohashi Medical Center, Tokyo, Japan

19 Department of Medical Statistics, School of Medicine, Toho University, Tokyo, Japan

20 Division of Cardiology and Catheterization Laboratories, Shonan Kamakura General Hospital, Kanagawa, Japan 